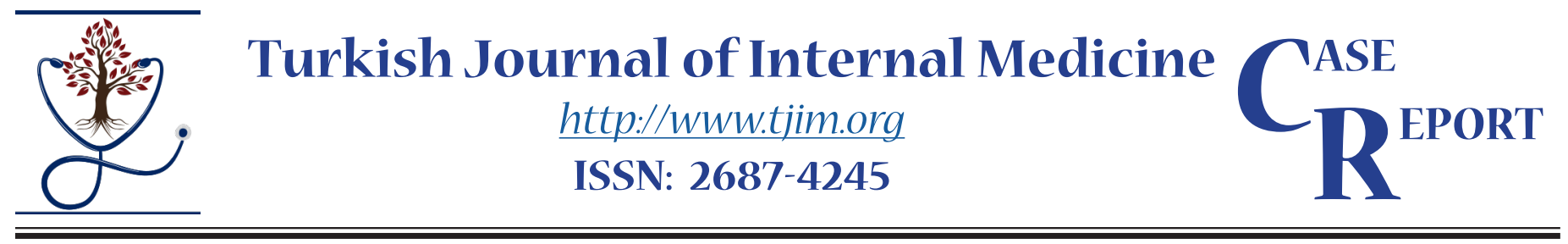

\title{
Herpes zoster ophthalmicus infection after kidney transplantation
}

\author{
Cihan Semet ${ }^{1}$, (D) Seray Türe 2 , Suat Akgür ${ }^{3}$ (D) Abdülmecit Yıldız, (D) Alparslan Ersoy \\ ${ }^{1}$ Department of Infectious Diseases and Clinical Microbiology, Bursa Uludag University Faculty of Medicine, Bursa, Turkey \\ ${ }^{2}$ Department of Internal Medicine, Bursa Uludag University Faculty of Medicine, Bursa, Turkey \\ ${ }^{3}$ Clinic of Nephrology, University of Health Sciences, Evliya Çelebi Training and Research Hospital, Kütahya, Turkey \\ ${ }^{4}$ Division of Nephrology, Department of Internal Medicine, Bursa Uludag University Faculty of Medicine, Bursa, Turkey
}

\begin{abstract}
Herpes zoster causes an acute dermatomal infection with vesicular rash associated with reactivation of the Varicella zoster virus. The infection usually involves the thoracic, cervical, ophthalmic and lumbosacral regions. Herpes zoster infection is common after solid organ transplantation. Herpes zoster ophthalmicus is a rare form of Herpes zoster infection and involves the ophthalmic branch of the trigeminal nerve along the V1-V2 dermatomes. Herein, we reported a kidney recipient who developed Herpes zoster ophthalmicus infection after transplantation.
\end{abstract}

Keywords: Herpes zoster, infection, kidney transplantation, ophthalmic involvement.

Turk J Int Med 2020;2(2):48-50

DOI: $10.46310 /$ tjim. 691092

\section{Introduction}

The infections after kidney transplantation are associated with significant morbidity and mortality. Herpes zoster (shingles) is caused by the reactivation of latent Varicella zoster virus (VZV), which gained access to sensory ganglia during varicella. Adult recipients are at high risk for the development of VZV-related disease (chickenpox and herpes zoster) after kidney transplantation due to long-term immunosuppression. ${ }^{1}$ VZV reactivation is increased in the elderly and immunocompromised individuals. It can cause an acute dermatomal infection, often accompanied by a vesicular rash that involves the thoracic, cervical, ophthalmic and lumbosacral regions. ${ }^{2}$ Herpes zoster ophthalmicus is defined as herpes zoster involvement of the ophthalmic branch of the fifth cranial (trigeminal) nerve along the V1-V2 dermatomes. It is characterized by painful unilateral vesicular eruption in different stages, and usually occurs in a restricted dermatomal distribution. We presented a kidney recipient who developed Herpes zoster ophthalmicus after transplantation. 


\section{Case Report}

A 48-year-old female patient underwent kidney transplantation 7 years ago due to end-stage kidney disease of unknown cause. Maintenance immunosuppressive therapy consisted of prednisolone, tacrolimus and mycophenolate mofetil (MMF). The patient was admitted to the emergency room with complaints of weakness, myalgia, headache and a yellow-dried vesicular rash extending to the forehead, nose, right eyelid and the scalp for the last 5 days (Figure 1a). In her laboratory tests; leukocyte was $7240 \mathrm{cell} / \mathrm{mm}^{3}$, hemoglobin $13.8 \mathrm{~g} / \mathrm{dL}$, platelet 230,000 cell $/ \mathrm{mm}^{3}$, creatinine $2.7 \mathrm{mg} / \mathrm{dL}$, AST 70 IU/L and ALT $132 \mathrm{IU} / \mathrm{L}$. With the diagnosis of herpes zoster ophthalmicus and peri-orbital cellulitis 750 $\mathrm{mg}$ acyclovir, $4 \mathrm{~g}$ ceftriaxone, $1200 \mathrm{mg}$ linezolid and $1000 \mathrm{mg}$ metranozidol treatments were started daily. Her endoscopic examination revealed no lesions compatible with rhinocerebral mucormycosis. On eye examination, keratitis was detected. Paranasal CT and orbital MR were compatible with pre-septal cellulitis. Wet spunch dressing treatments were added with local valgancyclovir, ciprofloxacin and saline. AST (21 IU/L) and ALT (58 IU/L) regressed on the $5^{\text {th }}$ day of parenteral treatment. Fever was not observed, headache complaint subsided, and edema around the eyelid completely disappeared. Some of the lesions were dried and some were completely disappeared (Figure 1b). The patient was discharged after 14 days of medical treatment.

\section{Discussion}

Herpes zoster ophthalmicus is a potentially sightthreatening condition. Its incidence rates varies from $8 \%$ to $20 \% .^{3-5}$ The prodromal period begins with headaches, malaise and fever. Unilateral pain or hypesthesia can be seen above the affected eye, forehead and top of head. Hyperemic conjunctivitis, uveitis, episcleritis and keratitis may occur at the onset of the rash. ${ }^{6}$ In our case with herpes zoster ophthalmicus due to cranial nerve involvement, keratitis was present. In VZV infections, the diagnosis is made by the presence of vesicles that form groups on erythematous ground in the skin region that characteristically correspond to the sensory nerve dermatome. In our patient, there were vesicular eruptions of the ophthalmic branch of the trigeminal nerve (V1) that formed groups in the area suitable for the dermatome area of the sensory nerve. Herpes simplex virus (HSV) infections, which may occasionally be typical shingles-like rashes, should also be considered in the differential diagnosis. Thoracolumbar region involvement is more common in Herpes zoster cases. ${ }^{7}$ Herpes IgM should be negative in VZV infection. In our patient, both herpes IgG and IgM were negative.

Reactivation is thought to be associated with suppression of cellular immunity. Herpes zoster keratitis and ophthalmicus are serious complications after cranial herpes infection. ${ }^{8}$ The incidence of Herpes zoster ophthalmicus in hospitalized immunosuppressive patients increases up to $35 \%$. Malignancy, radiotherapy or chemotherapy, organ transplantation and long-term corticosteroid use

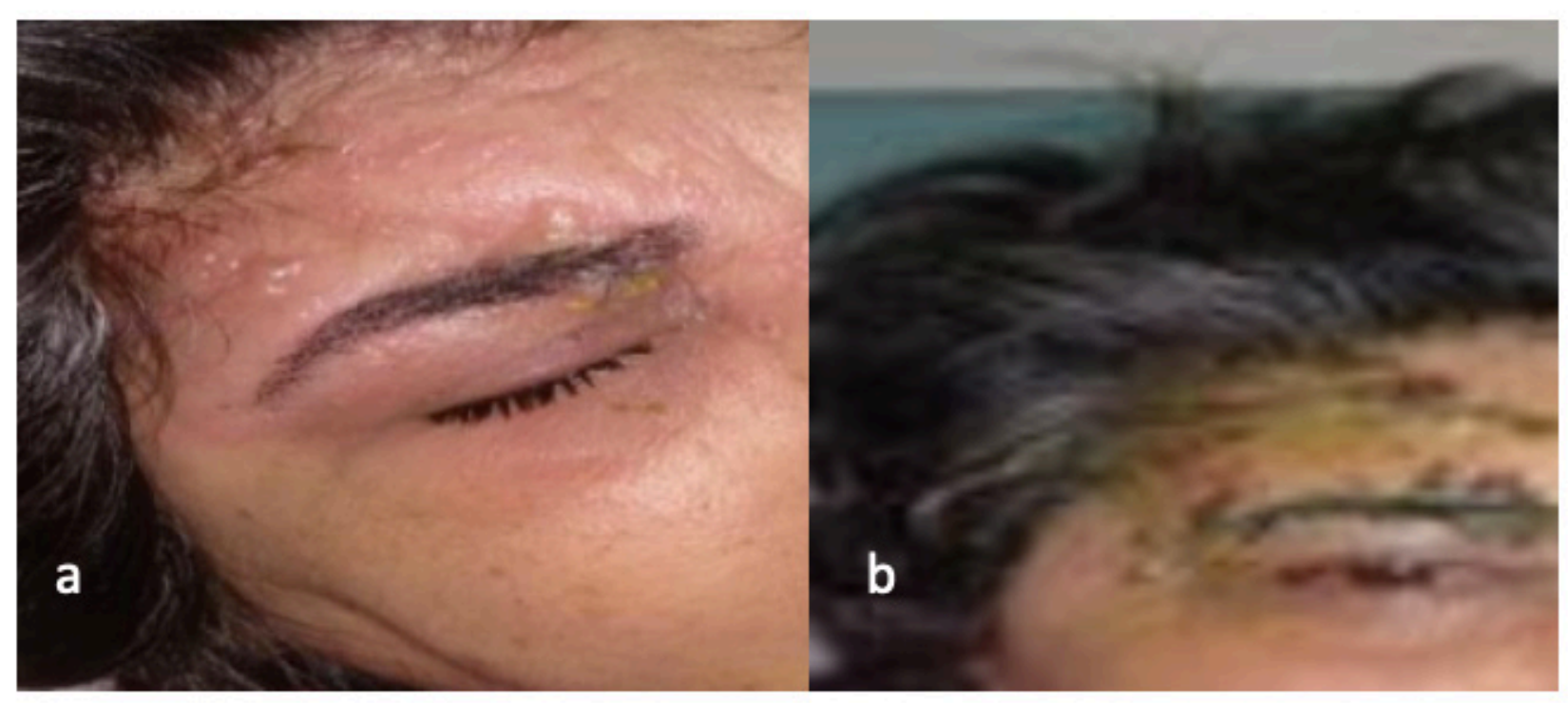

Figure 1. The appearrence of her eye involvement before (a) and after (b) the treatment 
are risk factors. Risk factors for the development of Herpes zoster in kidney transplant recipients are $>50$ years of age, long-term induction therapy and CMV prophylaxis. ${ }^{9}$ In some studies, MMF has been reported as a risk factor for Herpes zoster in kidney transplant recipients. Complications such as scar, encephalitis, hepatitis, disseminated intravascular coagulation and pneumonia may be observed after Herpes zoster infection. ${ }^{10}$ Our patient had hepatitis. Herpetic post-neuralgia (PNH) is a complication characterized by persistent pain that develops after acute pain and negatively affects quality of life and daily activities. Advanced age and the presence of immunosuppression are reported as factors associated with the development of PNH. ${ }^{11}$ Our patient did not develop PHN. Screening for VZV in adults and immunization to susceptible individuals before transplantation is recommended for the prevention of primary VZV infection in adult patients scheduled for kidney transplantation. ${ }^{12}$ Chickenpox vaccine can prevent the reactivation of the virus by increasing cellular immunity against the virus. Because VZV specific memory T-cell number decreases with age. When this decrease falls below the threshold, the risk of Herpes zoster development increases. Therefore, vaccine application can prevent Herpes zoster development by keeping VZV-specific T-cell formation above the threshold value. ${ }^{13}$ Complications such as primary varicella infection, recurrent zoster infections and pneumonia in immunocompromised patients are treated parenteral acyclovir (every 8 hours, $10 \mathrm{mg} / \mathrm{kg}$ ).

Ocular manifestations of Herpes zoster include lids, cornea, conjunctivae, uvea and retina involvements. The diagnosis of Herpes zoster may be difficult in immunosuppressed patients and should be considered in the differential diagnosis of acute headache in kidney transplant recipients. ${ }^{14}$ Occult infection is always possible, sometimes symptoms, signs, and routine tests can be misleading. Vesicular lesions on the side or tip of the nose are highly associated with eye involvement. Lesions in this area of the face indicate the involvement of the nasociliary branch of the trigeminal nerve. ${ }^{6}$ Therefore, early diagnosis and treatment of Herpes zoster infection after kidney transplantation is important to prevent progressive corneal involvement and potential vision loss.

\section{Conflict of interest}

The authors declared that there are no potential conflicts of interest with respect to the research, authorship, and/or publication of this article.

\section{References}

1. Chen SY, Suaya JA, Li Q, Galindo CM, Misurski D, Burstin S, Levin MJ. Incidence of herpes zoster in patients with altered immune function. Infection. 2014 Apr;42(2):325-34. doi: 10.1007/ s15010-013-0550-8.

2. Arness T, Pedersen R, Dierkhising R, Kremers W, Patel R. Varicella zoster virus-associated disease in adult kidney transplant recipients: incidence and risk-factor analysis. Transpl Infect Dis. 2008 Jul;10(4):260-8

3. Liesegang TJ. Herpes zoster ophthalmicus natural history, risk factors, clinical presentation, and morbidity. Ophthalmology. 2008 Feb;115(2 Suppl):S3-12. doi: 10.1016/j.ophtha.2007.10.009.

4. Pavan-Langston D. Herpes zoster ophthalmicus. Neurology. 1995 Dec;45(12 Suppl 8):S50-1.

5. Ragozzino MW, Melton LJ 3rd, Kurland LT, Chu CP, Perry HO. Population-based study of herpes zoster and its sequelae. Medicine (Baltimore). 1982 Sep;61(5):310-6.

6. Mary A Albrecht MA, Levin MJ. Epidemiology, clinical manifestations, and diagnosis of herpes zoster. In: Hirsch MS, Mitty J, editors. UpToDate [Internet]. Waltham (MA): UpToDate Inc; 2020 [cited $2020 \mathrm{Feb}$ ]. Available from: https://www.uptodate. com/contents/ epidemiology-clinical-manifestations-anddiagnosis-of-herpes.

7. Yawn BP, Saddier P, Wollan PC, St Sauver JL, Kurland MJ, Sy LS. A population-based study of the incidence and complication rates of herpes zoster before zoster vaccine introduction. Mayo Clin Proc. 2007 Nov;82(11):1341-9.

8. Galil K, Choo PW, Donahue JG, Platt R. The sequelae of herpes zoster. Arch Intern Med. 1997 Jun 9;157(11):1209-13.

9. Gourishankar S, McDermid JC, Jhangri GS, Preiksaitis JK. Herpes zoster infection following solid organ transplantation: incidence, risk factors and outcomes in the current immunosuppressive era. Am J Transplant. 2004 Jan;4(1):108-15.

10. Lauzurica R, Bayés B, Frías C, Fontseré N, Hernandez A, Matas L, Jimenez A, Bonet J, Romero R. Disseminated varicella infection in adult renal allograft recipients: role of mycophenolate mofetil. Transplant Proc. 2003 Aug;35(5):1758-9.

11. Hong MJ, Kim YD, Cheong YK, Park SJ, Choi SW, Hong HJ. Epidemiology of Postherpetic Neuralgia in Korea: An Electronic Population Health Insurance System Based Study. Medicine (Baltimore). 2016 Apr;95(14):e3304. doi: 10.1097/ MD.0000000000003304

12. Hata A, Asanuma H, Rinki M, Sharp M, Wong RM, Blume K, Arvin AM. Use of an inactivated varicella vaccine in recipients of hematopoietic-cell transplants. N Engl J Med. 2002 Jul 4;347(1):26-34

13. Kimberlin DW, Whitley RJ. Varicella-zoster vaccine for the prevention of herpes zoster. N Engl J Med. 2007 Mar 29;356(13):1338-43.

14. Ostermann ME, Gyawali P, Snowden SA, Eastwood JB, Streather CP. A 67-year-old kidney transplant patient with headache of uncertain origin. Nephrol Dial Transplant. 2002 Mar;17(3):50810. 